\title{
RANCANG BANGUN ALAT PEMBUKA DAN PENUTUP TONG SAMPAH OTOMATIS MENGGUNAKAN SENSOR JARAK BERBASIS ARDUINO
}

\author{
Stevania Hildegardis Bere, Ali Mahmudi, Agung Panji Sasmito \\ Program Studi Teknik Informatika S1, Fakultas Teknologi Industri \\ Institut Teknologi Nasional Malang, Jalan Raya Karanglo km 2 Malang, Indonesia \\ vannibere@gmail.com
}

\begin{abstract}
ABSTRAK
Kebersihan lingkungan adalah salah satu kegiatan untuk menciptakan lingkungan yang bersih, nyaman dan indah saat dipandang. Saat ini kesadaran akan kebersihan lingkungan sedang kurang optimal, buktinya masih banyak orang yang membuang sampah sembarangan, tempat sampah yang telah disediakan belum digunakan dengan baik. Masih ada masyarakat yang membuang sampah sembarangan karena takut kotor saat menyentuh tutup kotak sampah dan saat menginjak bagian kotak sampah untuk membuka tong sampah. Hal tersebut kurang praktis dan efisiensi untuk mewujudkan lingkungan yang bersih. Ada inovasi baru agar membuat kotak sampah lebih praktis namun tetap aman. Dengan memanfaatkan teknologi modern yaitu dengan membuat pembuka dan penutup kotak sampah otomatis dengan pengendalian otomatis dengan sensor jarak (ultrasonic), pengontrol untuk mengatur motor servo yang berfungsi untuk membuka dan menutup kotak sampah. Berdasarkan hasil perancangan dan pengujian sistem kepada 10 responden, maka dapat mengambil kesimpulan dari alat yang dibuat yaitu alat yang dirancang dapat bekerja dengan baik dalam menangani proses sistem membuka dan menutup tong sampah secara otomatis dengan jarak respon jika seorang melewati kotak sampah $<=30 \mathrm{~cm}$ maka tutup kotak sampah akan terbuka otomatis, dan delay selama 5 detik. Dapat mengirimkan notifikasi pesan telegram dengan baik saat buzzer memberikan alarm jika kotak sampah sudah penuh.
\end{abstract}

Kata Kunci : sensor jarak (ultrasonic), kotak sampah, motor servo.

\section{PENDAHULUAN}

Kebersihan lingkungan adalah salah satu kegiatan untuk menciptakan lingkungan bersih, nyaman, dan indah saat dipandang. Lingkungan yang bersih tidak hanya membuat orang merasa aman dan nyaman. Lingkungan bersih juga memberikan banyak manfaat, termasuk dalam mengendalikan penyakit. Karena lingkungan yang kotor merupakan sarang dari bibit penyakit berbahaya.

Perlu inovasi baru agar membuat kotak sampah lebih praktis dan aman. Dengan memanfaatkan teknologi modern yaitu dengan membuat pembuka dan penutup kotak sampah otomatis menggunakan metode yang dapat digunakan yaitu dengan pengendalian otomatis dengan beberapa sensor jarak (ultrasonic), pengontrol untuk mengatur motor servo yang berfungsi untuk membuka dan menutup kotak sampah.

Solusi yang ditawarkan dari produk yang dibuat untuk membantu mengurangi dampak permasalahan banjir, dan juga membantu menjaga kebersihan tangan dengan cara tidak langsung membuka kotak sampah tersebut. Orang membuang sampah dengan cara tidak langsung menyentuh penutup kotak sampah. Dewasa ini smart city menjadi idaman semua daerah, oleh karena itu dengan adanya produk skripsi ini bisa menjadi salah satu pendukung Samrt City tersebut.

\section{TINJAUAN PUSTAKA \\ 2.1. Penelitian Terdahulu}

Penelitian oleh pratama, dkk (2012) yang diakuisisi Data Kinerja Sensor Ultrasonic Berbasis Sistem Komunikasi Serial Menggunakan Mikrokontroler Atmega 32" Program Studi Pendidikan Teknik Elektro FPTK UPI ini bertujuan untuk merancang sistem akuisisi data kinerja sensor ultrasonic berbasis sistem komunikasi serial menggunakan mikrokontroler ATMega 32.

Penelitian oleh Elasya, dkk (2106) yaang berjudul "Aplikasi Sensor Ultrasonic Berbasis Mikrokontroler ATMEGA328 Untuk Merancang Tempat Sampah Pintar" Program Studi Teknik Elktro Fakultas Teknik Universitas Pakuan ini menjelaskan tentang tempat sampah pintar didefinisikan sebagai sebuah tempat sampah otomatis yang dimanfaatkan untuk memudahkan proses pembuangan sampah karen tidak diperlukan kontak langsung dengan penutupnya, sampah yang sudah penuh akan segera dibrsihkan karena terintegrasi langsung ke pengelola sampah. Secara garis besar alat sistem kendali tempat sampah pintar berbasis Mikrokontroler ATMega328 ini dibagi menjadi dua bagian, yaitu perancangan hardware dan perancangan software.

Penelitian oleh Anggraini dan Syeptiananda (2014) yang berjudul "Program Perancangan Kotak Sampah Otomatis Menggunakan Sensor PIR dan LDR Berbasis "Radio Control". Tempat sampah otomatis ini bekerja dikendalikan oleh mikrokontroler ATMega16 dngan compiler Bahasa Programming dasar (BASCOM AVR) dan remote control.

Rachmawati dan Pertiwi (2017) yang berjudul "Smart Environment Program, Smart Way to Smart 
City" Program Studi Public Administration Department Parahyangan Catholic University, melakukan penelitian tentang praktik smart city dalam aspek environment yang dijalankan oleh pemerintah kota Bandung. Berdasarkan penelitian tersebut digunakan 8 aspek sebagai alat analisa, salah satunya adalah manajemen pengelolaan sampah. Manajemen pengelolaan sampah yang dilakukan pemerintah kota Bandung dalam praktik smart environment adalah kerjasama antara Badan Pengelola Lingkungan Hidup(BPLH), perusahaan Dinas Kebersihan, dan Masyarakat kota Bandung untuk melakukan kegiatan sadar kebersihan.

\subsection{Arduino Uno R3}

Arduino uno merupakan sebuah board berbasis mikrokontroler pada Atmega328. Board ini mempunyai 14 digital input/output PWM (Pulse Width Modulator), 6 input analog MHZ osilator kristal, dan koneksi USB, jack listrik tombol reset. Pin pin pada mikrokontroler ini berisi semua yang diperlukan untuk mendukung mikrokontroler, hanya bisa terhubung dengan komputer menggunakan kabel USB atau sumber tegangan yang bisa didapat dari adaptor AC-DC atau baterai untuk menggunakannya. (Muklisin dkk, 2017).

Secara umum, Arduino terdiri atas dua bagian utama, yaitu:

a. Bagian Hardware

Berupa papan yang berisi I/O, seperti gambar 1 dibawah ini

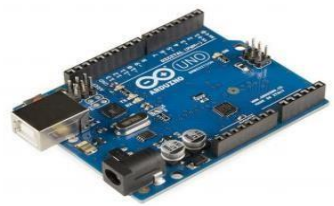

Gambar 1. Arduino Uno R3

b. Bagian Software

Menurut Sukarjadi, dkk (2017) software Arduino yang meliputi Integrated Development Enviroment (IDE) untuk menulis sebuah program. Arduino memerlukan sebuah instalasi driver untuk menghubungkan dengan komputer. Pada IDE terdapat contoh program dan library untuk mengembangkan program. IDE software Arduino yang digunakan diberi nama Sketch. Seperti Gambar dibawah ini :

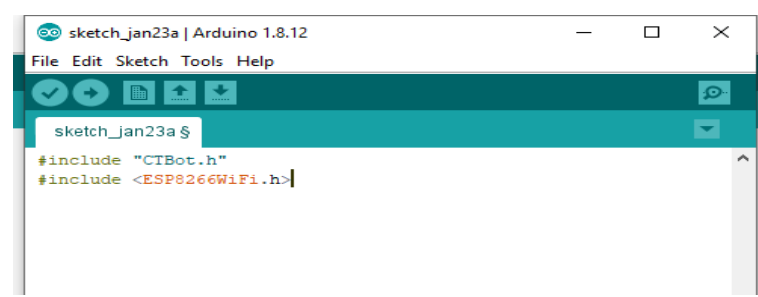

Gambar 2. Arduino IDE 6.2.5

\subsection{Sensor Ultrasonic}

Menurut (sukarjadi, 2017) "Sensor ultrasonic merupakan sensor yang berfungsi mengubah besaran fisis (bunyi) menjadi besaran fisis listrik dan sebaliknya. Cara kerja dari sensor ultrasonic berdasarkan pad prinsip dari pantulan suatu gelombang suara sehingga bisa dipakai untuk menafsirkan eksistensi (jarak) suatu benda dengan frekuensi tertentu".

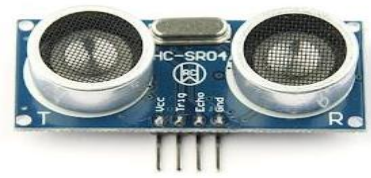

Gambar 3. Sensor Ultrasonic

\subsection{Servo Tower Pro SG60}

Menurut (Sukarjadi, 2017) memberikan teori bahwa "Motor Servo atau tower servo merupakan perangkat aktuator putar(motor) yang dirancang dengan sistem kontrol loop tertutup(servo), sehingga bisa diset-up dan di atur dalam menentukan posisi sudut dari proses output motor".

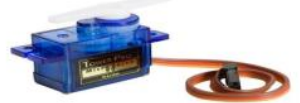

Gambar 4. Servo Tower

\section{5. $\mathrm{PCB}$}

PCB merupakan Printed Circuit Board, atau dalam bahasa Indonesia dikenal dengan istilah Papan Sirkuit Cetak. PCB merupakan alat penghubung komponen elektronik dalam komputer dengan jalur konduktornya.

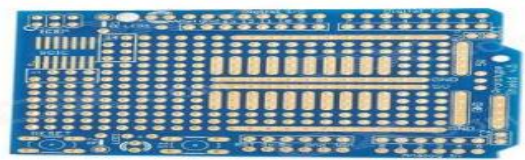

\subsection{Baterai}

Gambar 5 PCB

Accumulator storage battery adalah alat elektronika kimia yang dibuat untuk mensuplai listrik ke sistem starter mesin, sistem pengapian, lampulampu dan komponen kelistrikan lainnya. Alat ini merupakan sumber arus listrik yang searah yang dapat mengubah energi kimia menjadi energi listrik dan alat ini juga sebagai penyimpan daya listrik dari hasil reaksi kimia. Pada saat proses accukehilangan energi kimia, maka alternator mensuplainya kembali kedalam accu(yang disebut pengisian). Pengisian dan pengeluaran ini terjadi berulang kali dan terus menerus. (Hidayat, 2013. Battery)Arus yang berasal dari accumulatoryaitu arus searah atau arus DC. 


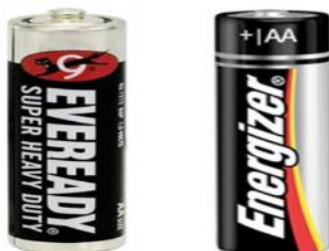

Gambar 6 Baterai

\subsection{Telegram}

Telegram telah menyediakan sebuah source code yang dapat digunakan. lalu yang kedua adalah tipe API yaitu memungkinkan siapa saja membuat sebuah bot di mana bot tersebut bisa mengirim pesan perintah yang bisa direspon oleh pengguna telegram yang telah mengakses bot tersebut. Bot juga bisa dikembangkan dengan bebas untuk siapa saja yang telah memiliki hak akses dengan bot tersebut (Buamonaa, 2019)

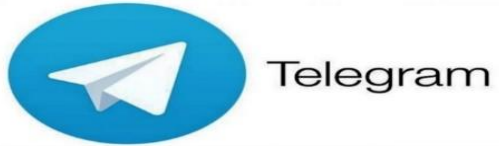

Gambar 7 Telegram

\subsection{Tempat sampah}

Tempah sampah merupakan sebuah wadah yang digunakan untuk menampung sampah secara sementara, tempat sampah biasanya terbuat dari plastik dan logam. Tempat sampah biasnya di tempatkan di dapur untuk membuang sisa keperluan dapur seperti botol atau kulit buah. Ada juga tempat sampah khusu untuk kertas yang biasanya di gunakan diperkantoran. Beberapa kotak sampah memiliki penutup diatasnya untuk menghindari keluarnya bau busuk daro sampah.

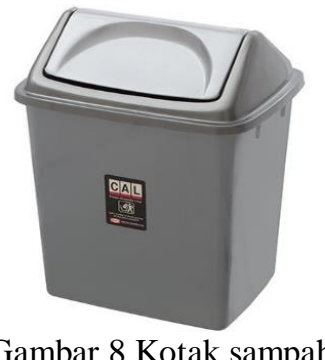

\subsection{Power supply}

Power supply merupakan suatu alat listrik yang dapat menyediakan energi listrik untuk perangkat listrik atau elektronika lainnya. Power supply membutuhkan sumber energi listrik untuk mengubahnya menjadi energi listrik yang dibutuhkan oleh perangkat elektronik lainnya. Power supply biasa disebut sebagai Electric Power Converter. (Dickson Kho, 2014)

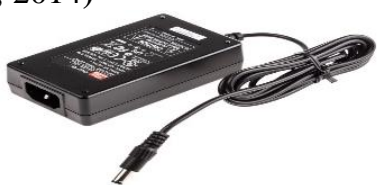

Gambar 9 Power Supply

\subsection{NodeMCU}

NodeMcu merupakan sebuah platform Iot yang mempunyai sifat opensource. NodeMcu terdiri dari perangkat keras dengan system On Chip ESP8266. Istilah NodeMcu secara default sebenarnya mengacu pada firmware yang digunakan dari pada peragkat keras development kit NodeMCU bisa dianalogikan sebagai board-nya ESP8266. (Sumardi, 2016).

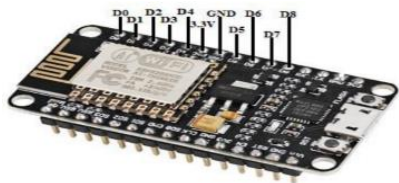

Gambar 10 NodeMCU

\section{ANALISIS DAN PERANCANGAN}

\subsection{Flowchart Sistem}

Flowchart sistem ini menjelaskan proses berjalannya aplikasi seperti ditunjukkan pada gambar 11.

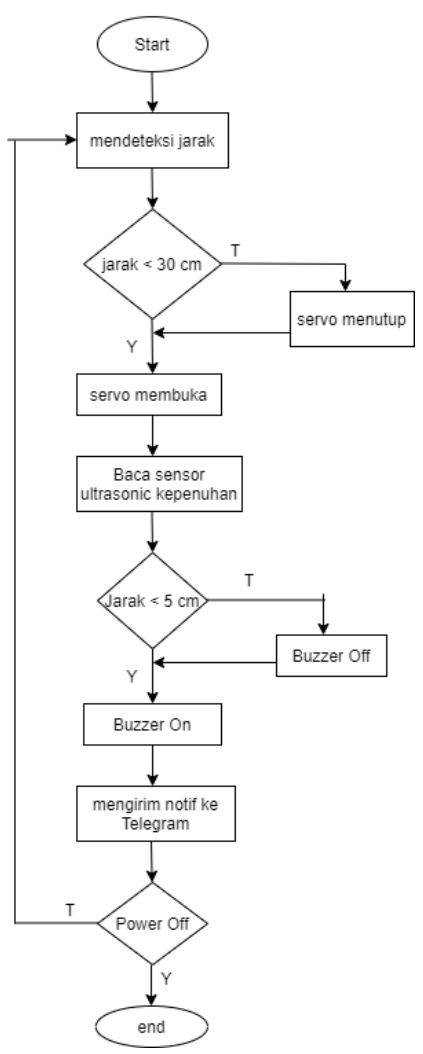

Gambar 11 Flowchart system

Berdasarkan flowchart pada gambar 11, merupakan diagram alur pada sistem monitoring buka tutup tempat sampah secara otomatis. Pada gambar 11 menceritakan proses sistem yang diawali dari sensor ultrasonic mendeteksi jarak orang yang melewati kotak sampah, jika orang melewati kotak sampah kurang dari $30 \mathrm{~cm}$ maka kotak sampah akan otomatis terbuka, motor servo akan bekerja untuk membuka penutup kotak sampah hingga 5 detik 
kemudian ditutup. Sensor ultrasonic yang kedua membaca kepenuhan sampah. Jika kotak sampah telah terisi dan sampah kurang dari $10 \mathrm{~cm}$ dari tutupan kotak sampah maka buzzer akan berbunyi dan akan mengirimkan notifikasi ke telegram

\subsection{Flowchart Alat}

Flowchart alat ini menjelaskan proses berjalannya alat seperti ditunjukkan pada gambar 12 .

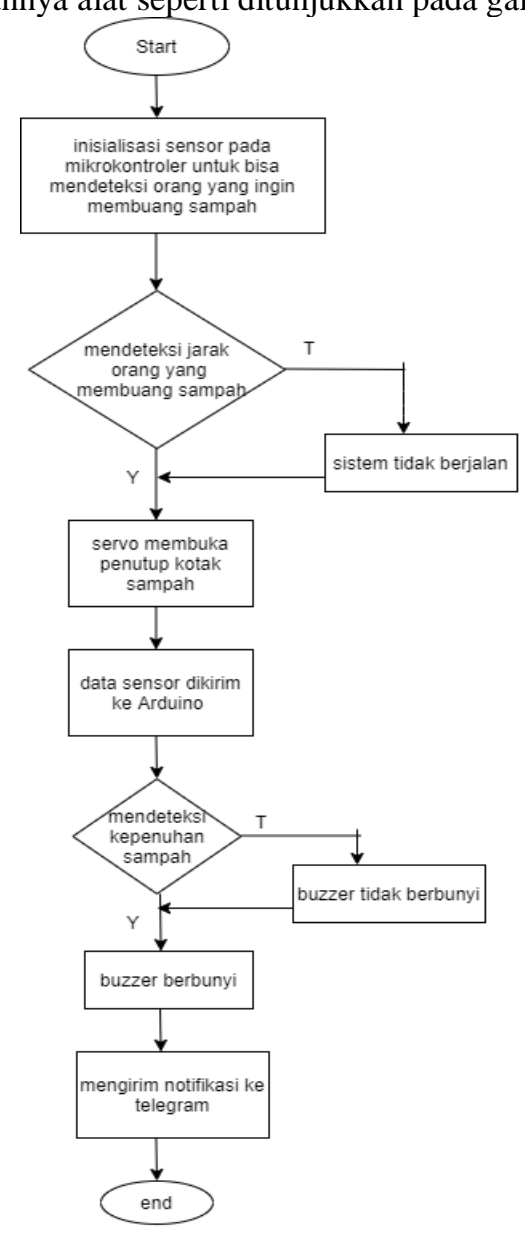

Gambar 12 Flowchart alat

Berdasarkan flowchart pada gambar 12, alur proses alat merupakan alur dari sistem monitoring tempat sampah untuk sensor. Pada gambar 12 menceritakan proses kerja alat yang diawali dari menginisialisasi sensor yang berfungsi untuk mengkonfigurasi sensor agar bisa mendeteksi kepenuhan pada kotak sampah. Jika kotak sampah penuh maka buzzer akan berbunyi dan akan mengirim notifikasi ke telegram dan data akan masuk ke website.

\subsection{Blok Diagram Sistem}

Blok Diagram Sistem adalah diagram dari sebuah sistem, dimana pada sensor jarak atas sebagai respon stimulus berupa pengukur jarak yang mengirimkan gelombang ultrasonic saat datangnya pantulan dari objek dan menghubungkan menjadi nilai, NodeMCU sebagai Arduino dan Module Wifi,
NodeMCU merupakan penghubung antara telegram dan website. Nilai dari sensor jarak disimpan pada database. Output data atau hasil akhir ditampilkan pada website, dan monitoring dilakukan langsung pada website. Telegram menerima notifikasi masuk jika kotak sampah sudah terisi penuh. Proses kerja pada alat ini ditunjukkan pada gambar 13 berikut.

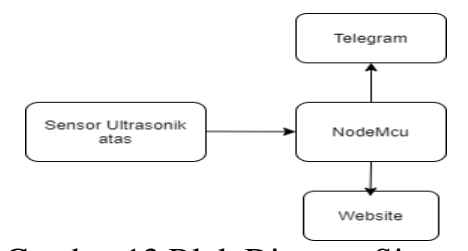

Gambar 13 Blok Diagram Sistem

\subsection{Desain Sistem}

Dalam proses pengumpulan data-data untuk mendapatkan informasi dari monitoring sampah otomatis untuk mendapatkan data dari sensor ultrasonik depan dan sensor ultrasonik atas yang selanjutnya akan dilakukan pengolahan dan pengembangan kedalam website melalui proses berjalannya alat. hasil output tersebut bisa dilihat pada gambar 14 berikut.

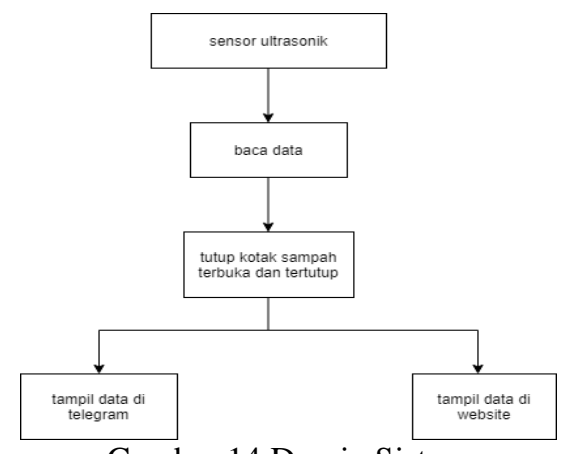

Gambar 14 Desain Sistem

\section{HASIL DAN PEMBAHASAN}

4.1. Pengukuran Sensor Jarak HCSR04

Hasil pengujian jarak sensor HCSR04 menggunakan penggaris dan hasil pengolahan data HCSR04 yang ditampilkan serial monitor Arduino.

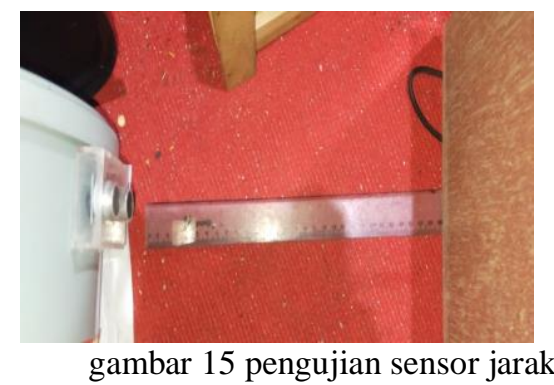




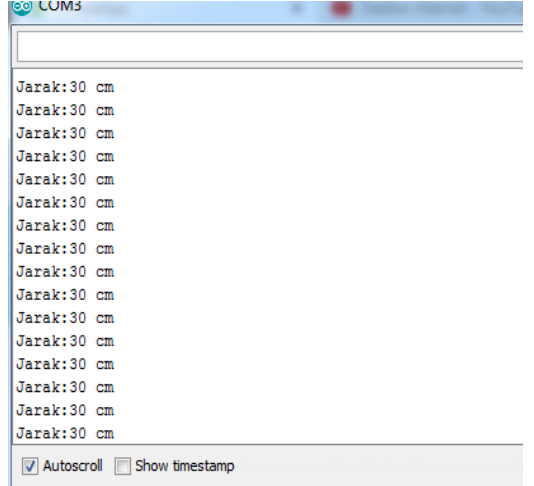

Gambar 16 pengujian hasil sensor jarak

Tabel 1 Pengujian Jarak

\begin{tabular}{|l|l|l|l|}
\hline No & $\begin{array}{l}\text { Jarak } \\
(\mathrm{cm})\end{array}$ & $\begin{array}{l}\text { Hasil } \\
\text { ukur }\end{array}$ & $\begin{array}{l}\% \\
\text { Eror }\end{array}$ \\
\hline 1 & 10,2 & $10 \mathrm{~cm}$ & 1,96 \\
\hline 2 & 15,4 & $15 \mathrm{~cm}$ & 2,5 \\
\hline 2 & 24 & $24 \mathrm{~cm}$ & 0 \\
\hline 3 & 30 & $30 \mathrm{~cm}$ & 0 \\
\hline 4 & 50,2 & $50 \mathrm{~cm}$ & 1,96 \\
\hline 5 & 100 & $100 \mathrm{~cm}$ & 0 \\
\hline
\end{tabular}

Berdasarkan perhitungan dan hasil pengujian sebagaimana pada tabel 1 hasil yang di dapat sesuai dengan pengukuran yang ditampilkan pada serial monitor, namun pada pengukuran beberapa jarak didapat eror pada hasil pengukuran dan pembacaan. Toleransi error pada pengukuran dirumuskan sebagai berikut

Error $=\frac{\text { Hasil_Ukur }- \text { jarak_ukur }}{\text { Jarak_ukur }} \times 100 \%$

\subsection{Hasil Pengujian}

Dari hasil pengujian sebagaimana tabel 1 didapat hasil pembacaan data menggunakan software yang ditampilkan pada serial monitor. Hasil pengujian tersebut mempunyai selisih namun tidak terlampaui jauh. Hal ini disebabkan karena faktor pembiasaan suara(bursting) dalam pengukuran jarak sensor HCSR04 sangat bergantung pada media yang menghalangi pancaran gelombang ultrasonic tersebut sehingga didapat nilai pembacaan sebagaimana pada tabel 1. Dikarenakan hasil pengujian yang didapat mempunyai toleransi error yang sedikit, maka sensor HCSR04 tersebut masih dinyatakan bekerja dengan baik dalam melakukan pengukuran.

\subsection{Pengujian Motor Servo}

Untuk pengujian motor servo, menggunakan perangkat lunak dimana variable PMW dirubah mulai dari 0 hingga $255(8$ bit PWM), dimana perangkat lunak bertugas untuk mngatur PWM dan servo bergerak sesuai derajat putaran. Dari hasil percobaan didapat perubahan derajat motor mnggunakan table 2 berikut :
Tabel 2 Pengujian Motor Servo

\begin{tabular}{|c|c|c|}
\hline No & Data PWM & Posisi motor (derajat) \\
\hline 1 & 0 & $-90^{\circ}$ \\
\hline 2 & 10 & $-80^{\circ}$ \\
\hline 3 & 50 & $-60^{\circ}$ \\
\hline 4 & 100 & $-30^{\circ}$ \\
\hline 5 & 127 & $0^{\circ}$ \\
\hline 6 & 150 & $50^{\circ}$ \\
\hline 7 & 200 & $70^{\circ}$ \\
\hline 8 & 255 & $90^{\circ}$ \\
\hline
\end{tabular}

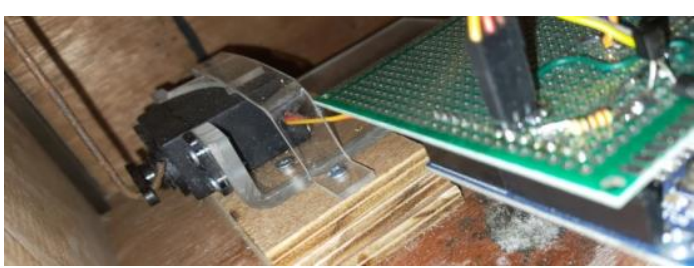

Gambar 17 Pengujian Motor Servo (PWM=100)

Berdasarkan hasil pengujian, PWM dibangkitkan dari perangkat lunak dengan nilai variasi PWM 8bit $(0-255)$ pada kondisi -90o s.d 90o. Pada kondisi ini lebar pulsa TH dan TL berbahubah sesuai lebar pulsa PWM yang dibangkitkan oleh perangkat lunak. Karena pada motor servo telah dilengkapi controller internal yang mengatur masukan PWM berdasarkan arah, maka pada kondisi PWM tertentu motor servo menunjuk ke posisi derajat tertentu pula dengan step perubahan -90 hingga 90o pergeseran tuas motor. Dengan demikian, maka pengujian motor servo bekerja dengan baik.

\subsection{Pengujian Buzzer}

Dari hasil uji coba pada buzzer maka mendapatkan hasil seperti pada tabel 3 berikut ini :

Tabel 3 pengujian buzzer

\begin{tabular}{|l|l|l|l|}
\hline No & $\begin{array}{l}\text { Input(pin D12 } \\
\text { Arduino) }\end{array}$ & $\begin{array}{l}\text { Kondisi } \\
\text { Buzzer }\end{array}$ & Tegangan \\
\hline 1 & $0(\mathrm{GND})$ & Bunyi & 11,4 Volt \\
\hline 2 & $1(5 \mathrm{~V} / \mathrm{Vcc})$ & Diam & 0,3 Volt \\
\hline
\end{tabular}

Berdasarkan pengujian menggunakan driver buzzer ditunjukkan dalam tabel 3 saat input diberikan logika low (1), maka keadaan tersebut menyebabkan buzzer berbunyi sementara pada pengujian tegangan menggunakan avometer didapat 4,8V. Saat pin 12 diperintah mengeluarkan logika 0 (low) maka buzzer mati dan tidak berbunyi sebagaimana pengujian pada tabel 3 dengan demikian maka buzzer bekerja dengan baik

\subsection{Pengujian NodeMcu send Telegram}

Dari hasil pengujian didapat hasil seperti yang ditunjukkan dalam gambar 


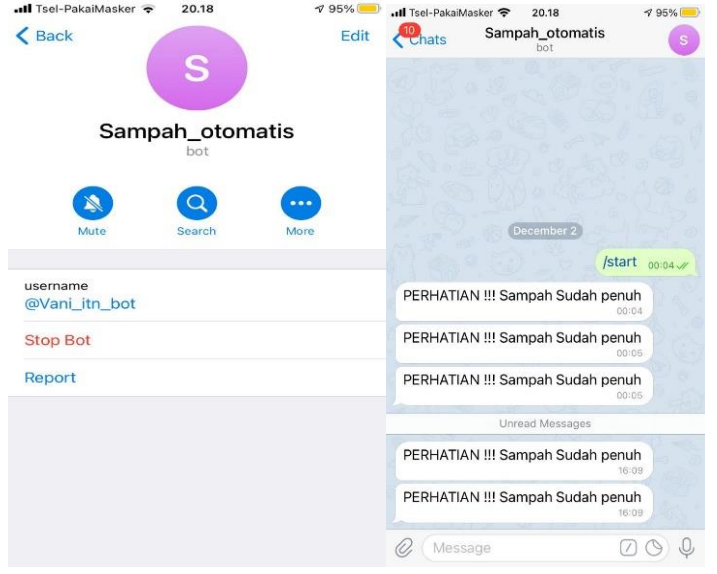

Gambar 18 Hasil pengujian Telegram

Perangkat lunak dirancang menggunakan library "CTBot.h" yang bertugas menangani proses send read message telegram. Pada potongan program diatas, nodemcu melakukan koneksi wifi melalui SSID dan password. Selanjutnya melakukan koneksi ke server telegram bot dengan kunci dari token yang didapat saat mendaftar bot pada telegram. Token ini digunakan untuk mengakses bot server telegram sehingga suatu proses send read data akan terkirim ke bot tersebut, sementara id digunakan untuk mengirim ke id telegram user sehingga pesan dengan nama bot yang didaftar akan diterima oleh perangkat seluler dimana id telegram tersebut didaftarkan. Adapun hasil pengujian dengan mengirim pesan sampah penuh sebagaimana pada perangkat lunak didapat hasil sebagaimna tampilan screenshot pada gambar 10. Dengan demikian, maka pada pengujian ini bekerja dengan normal.

\subsection{Pengujian Keseluruhan}

Pada pengujian pertama alat ditempatkan pada ruang terbuka dan tanpa halangan untuk melihat respon. Dari hasil pengujian alat (tempat sampah) didapat hasil pada gambar 19

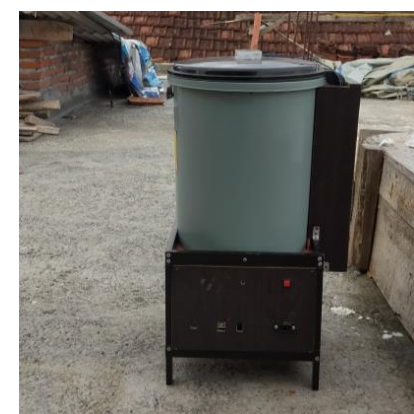

Gambar 19 pengujian alat pada kondisi tanpa halangan

Pada pengujian ini alat diuji coba tanpa ada halangan, dimana system bekerja dan batteray backup didalamnya. Dari hasil pengujian, tempat sampah ini tidak merespon apapun namun alat tetap standby.

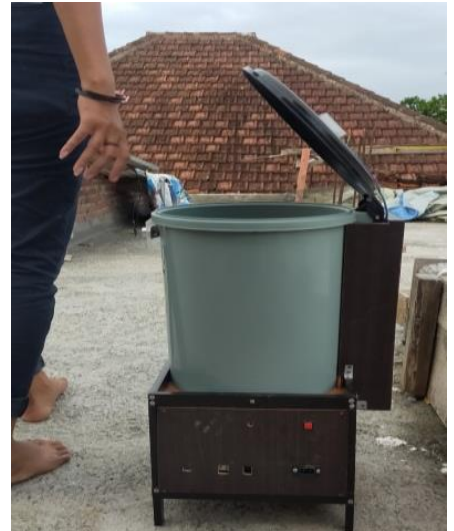

Gambar 20 Pengujian alat pada kondisi dengan halangan

Dari hasil pengujian sebagaimana gambar 20 diketahui bahwa tempat sampah merespon dengan membuka tutup atas tempat sampah melalui motor servo. Alat merespon setelah terdapat objek didepan sensor dan menutup kemudian jika selama 5 detik tidak terdapat halangan.

Adapun pengujian jarak respon halangan yang dapat dikendalikan ditunjukkan pada gambar 13

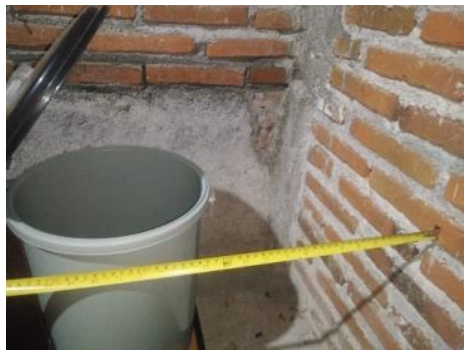

Gambar 21 pengujian alat pada jarak $30 \mathrm{~cm}$

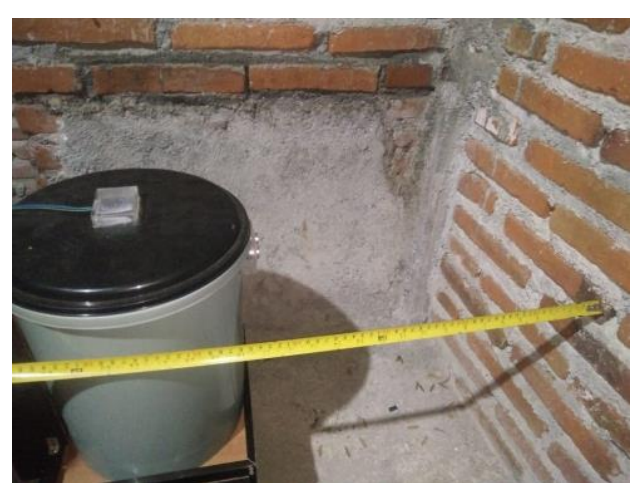

Gambar 22 pengujian alat pada jarak $45 \mathrm{~cm}$

\subsection{Pengujian User}

Pengujian user bertujuan untuk menghasilkan dokumen yang dijadikan bukti bahwa sistem sudah berjalan dengan baik atau belum, pengujian ini diuji coba kepada 10 orang pengguna dengan skala 4 yaitu, TB (tidak baik), KB (kurang baik), B (baik), SB (sangat baik) dan dengan kuisioner berisi 6 pertanyaan tentang alat yang dibuat. 
Penilaian :

1. $\mathrm{TB}=$ Tidak Baik

2. $\mathrm{KB}=$ Kurang Baik

3. $\mathrm{B}=$ Baik

4. $\mathrm{SB}=$ Sangat Baik

Table 5 uji coba keseluruhan

\begin{tabular}{|c|c|c|c|c|c|}
\hline \multirow{2}{*}{ No. } & \multirow{2}{*}{ Pernyataan } & \multicolumn{4}{|c|}{10 Responden } \\
\hline & & TB & KB & B & SB \\
\hline \multicolumn{6}{|c|}{ Sensor Ultrasonic } \\
\hline 1. & $\begin{array}{l}\text { Apabila } \\
\text { pengguna } \\
\text { mendekati } \\
\text { sensor ultrasonic } \\
\text { pada jarak }<=30 \\
\text { cm maka kotak } \\
\text { sampah akan } \\
\text { terbuka }\end{array}$ & 0 & 0 & 7 & 3 \\
\hline 2. & 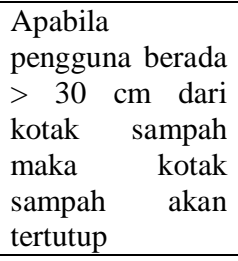 & 0 & 0 & 10 & 0 \\
\hline \multicolumn{6}{|c|}{ Buzzer } \\
\hline 1 & $\begin{array}{l}\text { Pada saat kotak } \\
\text { sampah penuh } \\
\text { maka buzzer } \\
\text { akan berbunyi }\end{array}$ & 0 & 0 & 10 & 0 \\
\hline 2 & $\begin{array}{l}\text { Pada saat kotak } \\
\text { sampah belum } \\
\text { terisi penuh } \\
\text { maka buzzer } \\
\text { tidak berbunyi }\end{array}$ & 0 & 0 & 8 & 2 \\
\hline \multicolumn{6}{|c|}{ Notifikasi Telegram } \\
\hline 1 & $\begin{array}{l}\text { Apabila kotak } \\
\text { sampah terisi } \\
\text { penuh maka akan } \\
\text { mengirimkan } \\
\text { notifikasi } \\
\text { telegram }\end{array}$ & 0 & 0 & 4 & 6 \\
\hline 2 & $\begin{array}{l}\text { Apabila kotak } \\
\text { sampah belum } \\
\text { terisi penuh maka } \\
\text { tidak akan } \\
\text { mengirimkan } \\
\text { notifikasi } \\
\text { telegram }\end{array}$ & 0 & 0 & 1 & 9 \\
\hline & Total & 0 & 0 & 40 & 20 \\
\hline & Persentase & 0 & 0 & $66 \%$ & $33 \%$ \\
\hline
\end{tabular}

Dari data uji coba pada keseluruhan alat dapat disimpulkan bahwa semua komponen pada sistem ini bisa berjalan seperti yang diharapkan, di mana sensor ultrasonic mendeteksi orang yang melewati kotak sampah $<30 \mathrm{~cm}$ motor servo bekerja untuk membuka tutup kotak sampah. Jika sensor membaca kepenuhan kotak sampah maka buzzer berbunyi dan akan mengirimkan notifikasi pada telegram.

\section{KESIMPULAN DAN SARAN}

\subsection{Kesimpulan}

Berdasarkan hasil rancangan dan pengujian alat secara keseluruhan, maka dapat diambil kesimpulan sebagai berikut:

1. Modul ultrasonic yang dirancang mampu mendeteksi dengan baik jarak halangan pada proses pembukaan tempat sampah dan ketinggian tempat sampah.

2. Motor servo yang dirancang dapat melakukan pembukaan dan penutupan tutup tempat sampah melalui mekanik secara akurat dengan perangkat lunak PWM yang telah terkalibrasi.

3. NodeMcu yang dirancang mampu melakukan notifikasi pesan pada telegram dengan bantuan perangkat lunak dan router.

4. Alat yang dirancang dapat bekerja dengan baik dalam menangani proses sistem terbuka dan tertutup tempat sampah secara otomatis dengan jarak respon dibawah $30 \mathrm{~cm}$ dan dapat mengirimkan notifikasi pesan telegram dengan baik.

\subsection{Saran}

Berdasarkan hasil penelitian yang dilakukan, maka penulis memberikan saran untuk pengembang selanjutnya seperti :

1. Pada penelitian selanjutnya bisa mengembangkan sistem mekanik menjadi 2 jenis yaitu sampah kering dan sampah basah.

2. Pada penelitian selanjutnya bisa dikembangkan menggunakan sensor yang tahan air.

3. Pada penelitian selajutnya bisa ditambahkan alat pengepres sampah.

\section{DAFTAR PUSTAKA}

[1] Pratama, dkk. 2012. "Akuisisi Data Kinerja Sensor Ultrasonic Berbasis Sistem Komunikasi Serial Menggunakan Mikrokontroler Atmega32".

[2] Elasya, dkk. 2016. "Aplikasi Sensor Ultrasonic Berbasis Mikrokontroler ATMEGA328 Untuk Merancang Tempat Sampah Pintar". Universitas Pakuan.

[3] Anggraini dan Syeptiananda. 2014. "Program Perancangan Kotak Sampah Otomatis Menggunakan Sensor PIR dan LDR Berbasis Radio Control".

[4] Rachmawati dan Pertiwi. 2017. "Smart Environment Program, Smart Way to Smart City “.

[5] Angga Dwi Mulyanto. 2020. "Pemanfaatan Bot Telegram Untuk Media Informasi Penelitian".

[6] Yudha maulana. 2020. "inSWA: Masalah Sampah diIndonesia Sudah Stasiun Lima”. 